\title{
A CONSTRUÇÃO DA IDENTIDADE GUARANI NO PERÍODO COLONIAL
}

\author{
Celuniel Aquino Valiente ${ }^{1}$ \\ Rogerio de Palma ${ }^{2}$
}

RESUMO: Com o intuito de fornecer subsídios para o entendimento da instituição do saber colonial, o artigo pretende esboçar uma análise acerca de como se construiu, ao longo do período colonial, uma identidade "guarani" entre as sociedades indígenas que estão situadas no atual estado de Mato Grosso do Sul. Através do exame da bibliografia sobre o tema, percebeu-se que a construção, tanto material/territorial como simbólica, de grupos sociais que se identificam (ou são identificados) como "guarani" somente pode ser compreendida por meio da análise das experiências políticas, impostas pelos colonizadores, que tentaram uniformizar e subalternizar sociedades culturalmente heterogêneas.

Palavras-chave: Identidade; Guarani; Colônia.

\section{THE CONSTRUCTION OF THE GUARANI IDENTITY IN THE COLONIAL PERIOD}

\begin{abstract}
In order to provide support for the understanding of the institution of colonial knowledge, the article intends to sketch an analysis of how a "Guarani" identity was constructed during the colonial period between the indigenous societies that are located in the present state The study, both material / territorial and symbolic, of social groups that identify themselves (or are identified) as "Guarani" can only be understood through of the analysis of political experiences imposed by the colonizers, who tried to standardize and subalternize culturally heterogeneous societies.
\end{abstract}

Keywords: Identity; Guarani; Cologne.

\section{INTRODUÇÃO}

A colonização europeia ao longo do continente americano, ocorrida entre os séculos XV e XIX, produzui uma forma específica de mentalidade, especialmente um tipo de conhecimento sobre o Outro, denominado de colonialidade. Conforme afirma Anibal Quijano (2005, p. 117), "a América constitui-se como o primeiro espaço/tempo de um padrão de poder de vocação mundial e, desse modo e por isso, como a primeira id-entidade da modernidade".

\footnotetext{
${ }^{1}$ Graduação em Ciências Sociais pela Universidade Estadual de Mato Grosso do Sul - UEMS, Graduando em Licenciatura Intercultural Indígena Teko Arandu - habilitação em Ciências Humanas na Faculdade Intercultura Indígena da Universidade Federal da Grande Dourados (FAIND-UFGD) e Mestrando em Antropologia (pelo Programa de Pós Graduação em Antropologia - PPGAnt da Faculdade de Ciências Humanas - UFGD. Contato: celunielvaliente@gmail.com

${ }^{2}$ Graduou-se em Ciências Sociais (2007) pela Universidade Federal de São Carlos. Possui mestrado (2010) e doutorado (2014) em Sociologia pela mesma instituição. Professor Adjunto da UEMS/Amambai, lecionando e orientando pesquisas no curso de Ciências Sociais e História desta Unidade. Contato: rpalma@uems.br
} 
Ancorado no poder dos colonizadores sobre os colonizados, a colonização do continente produziu determinadas formas de classificação (índio, negro, mestiço, europeu etc.) que foram - e ainda são - essenciais para se pensar as relações sociais nesse contexto. No entanto, mesmo o fim oficial do período colonial, ou seja, os processos de independência dos países que estavam sob o julgo de países europeus, não foram capaz de causar, necessariamente, o fim da mentalidade colonial. De acordo com Quijano, mesmo após a independência, o pensamento colonial permaneceu colonizando as ações que diversos grupos sociais.

Nesse sentido, a colonialidade é um jeito de ser que inferioriza o Outro, que categoriza o Outro sempre a partir da ausência ou da inferioridade. Exemplificando, a colonialidade é o pensamento que sustenta a crença de que o branco é melhor que indígena. É a crença, entre os colonizados, de que o Outro é mais sábio, a crença de que a comida do Outro é mais gostosa, a língua do Outro é mais bonita, a igreja do outro é mais santa, ou seja, o de fora é mais e o do dentro é menos. Resumindo, sob a ótica do pensamento colonial, o branco é futuro/progresso/desenvolvimento e as sociedades indígenas, passado/atraso/retrocesso.

Tentando fornecer subsídios para o entendimento da construção desse saber/mentalidade colonial, o artigo pretende esboçar uma análise acerca de como se construiu, ao longo do período colonial, uma identidade "guarani" entre as sociedades indígenas que hoje habitam o estado de Mato Grosso do Sul. Através do exame da bibliografia sobre o tema, percebeu-se que a construção, material e simbólica, de grupos sociais que se identificam (ou são identificados) como "guarani" somente pode ser compreendida por meio da análise das experiências coloniais que tentaram uniformizar e subalternizar sociedades culturalmente heterogêneas. O que aqui conceituamos de período ou sociedade colonial não é um quadro monolítico, mas abriga uma grande heterogeneidade social, tanto espacial como temporalmente. Porém, tomamos a ideia de colônia como referência pois ela é essencial para refletirmos sobre a experiência de construção de determinadas identificações que serão aqui abordadas.

\section{GUARANI FALANTES NO PERÍODO COLONIAL}

Durante o período colonial, diversos cronistas europeus produziram relatos acerca dos povos falantes da língua guarani, sendo que essas descrições transformaram-se em formas de classificação e caracterização dessas populações. Tais cronistas escreviam cartas sobre os nativos americanos a fim de levar informações para a Europa sobre a ocupação dessa vasta região. Exemplos são a carta de Luis Ramirez (1594); a carta de Padre Alonso Barzana 
(1594); Padre Antonio Ruiz de Montoya (1639); Diego Garcia; Pero Lopes de Souza; Alvar Nuñes Cabeza de Vaca entre outros cronistas que descreviam os povos nativos. É justamente no período colonial que se construíram diversas identificações e significados que caracterizavam as populações nativas através desses relatos etnográficos. $\mathrm{Na}$ atualidade, encontram-se diversos livros e artigos que discutem as descrições produzidas durante o período colonial, principalmente pelos antropólogos e historiadores. Muitas vezes, a finalidade dos pesquisadores dessas áreas é justamente superar essas teorias que se fundamentaram nesse paradigma colonial.

O livro Reduções Jesuítico-Guarani: espaço de diversidade étnica, do historiador André Luis Freitas da Silva, analisa a situação dos Guarani falantes no período colonial, as diversidades étnicas e os seus contatos com os colonizadores. Esse trabalho contribui muito para compreendermos as origens das identificações e significações Guarani nesse contexto. Outra pesquisadora desta área é Graciela Chamorro. O trabalho dela vem contribuindo bastante em torno desta área desde início da sua produção cientifica. O seu livro Historia Kaiowá (2015) é uma grande contribuição para compreendermos a situação atual dos Kaiowá. Chamorro estuda profundamente as populações que hoje se situam no Sul de Mato Grosso do Sul, tentando ao máximo compreender as realidades e as histórias desses grupos.

Antes da chegada dos conquistadores europeus, povos indígenas viviam dispersos nessa vasta região do Brasil, geralmente construindo seus espaços de moradia nas margens dos rios. Os povos nativos possuíam pluralidade étnica, com culturas e línguas diversas. No que diz respeito ao Guarani falantes, uma das principais sustentações desse grupo seria o cultivo de milho, além da pesca, da caça e da agricultura de coivara (uma técnica de plantação onde, primeiramente, derrubam-se as árvores e depois queimam o espaço para se poder plantar). Devido isso, muitos estudiosos afirmam que, possivelmente, os Guarani são de origem amazônica. Por fatores como busca de melhores condições de vida (cultural e ambiental), teriam migrado para o sul.

Os índios Guarani foram e são excelentes agricultores. Estes cultivavam principalmente o milho, base de sua dieta alimentar. Eram eficientes no cultivo e tecelagem do algodão silvestre, matéria-prima para a confecção de redes e vestimentas. Produziam ainda uma diversificada coleção de recipientes de cerâmica, utilitária e ritual, ricamente decorada, utilizada inclusive para o sepultamento de seus mortos (MARTINS, 2002, p. 41). 
Não há nenhuma dúvida de que os Guarani falantes já se situavam anteriormente à chegada do conquistadores europeus nessa vasta região que hoje conhecemos como a fronteira entre Brasil e Paraguai.

\begin{abstract}
A presença indígena na região onde está inserido o atual estado de Mato Grosso do Sul é sem duvida muito anterior à passagem dos primeiros conquistadores europeus pelo lugar. Mas é muito pouco o que sabemos desses indígenas. O que sabemos sobre essa épocas mais remotas provêm de duas ciências: arqueologia, que estuda a existência humana no tempo a partir de vestígio da cultura material, e a Glotocronologia, que estuda a separação temporal entre línguas emparentadas.

[...] não se pode afirmar com segurança que os Kaiowá e Guarani contemporâneos sejam descendentes diretos dos povos da tradição "Tupiguarani”. E mesmo se assim fosse, é necessário considerar que existem - durante os 1500 anos de separação entre os antigos ceramistas e os povos atuais - uma enorme profundidade histórica, com todas as mudanças possíveis de ocorrer durante esse longo período (CHAMORRO, 2015, p. 49-50).
\end{abstract}

Estudos arqueológicos sugerem que os antepassados dos Guarani começaram a ocupar o Sul e o Sudeste brasileiros muitos anos antes de os portugueses e espanhóis aportarem no Novo Mudo e tornarem-no semelhante ao Velho (SOUSA, 2004, p. 30). Durante o período colonial, através de guerras e da transmissão de doenças, a colonização europeia acabou por dizimar os Tupi Guarani e outros grupos indígenas. No interior dos Guarani falantes existem diversas designações. Somente na atual região do estado de Mato Grosso do Sul, temos os kaiowá, Mbya e Nahndeva. Entretanto, no período colonial existiam Chiriguano, Carijó ou Cario, Mbyasá, Tobatí, Itatim e Tape. Na região do atual Bacia Hidrográfica do Rio Prata, em suas margens, habitavam diversos povos que falavam o Guarani, mas com estilos de vida bastante distintos.

\title{
QUEM SÃO OS GUARANI NO PERÍODO COLONIAL?
}

Conforme citado acima, existem vários relatos sobre os Guaranis feitos por diferentes cronistas. Neste presente tópico discutiremos esse tema a fim de tentar mostrar como eram identificadas as populações nativas que se situavam no atual estado de Mato Grosso do Sul. Em 1528, foi encontrado pela primeira vez o termo guarani, que foi a denominação dada às populações que habitavam a atual fronteira entre Brasil e Paraguai. Estava presente exatamente na carta de Luis Ramirez endereçada ao seu pai, que havia permanecido na Europa. Nessa carta foram identificadas diversas populações classificadas sob o rótulo de guarani. Os colonos acreditavam que era um povo que compartilhava a mesma língua e algumas características culturais uns com outros. Segundo Montoya, a palavra "guaryni" 
significa guerra, sendo "aguaryni" o mesmo que guerrear (Feitas da Silva, 2012, p. 38). As supostas características de agressividade e de propensão à guerra teriam levado os europeus a classificarem essas populações por meio do termo "guaryni". É a partir dessa palavra que se passa a determinar todos os habitantes existentes nesse território.

Nesse sentido, diferentes grupos étnicos passaram a ser apontados pela mesma nomeação, especialmente a partir da sua língua, mesmo possuindo estilos de vidas ou hábitos distintos.

Conforme Bartomeu Melià, guaryni possivelmente era uma autodenominação desses indígenas das ilhas que se generalizou para outras populações como língua e característica socioculturais semelhantes. Tal como os Carijó contatados na Ilha de Santa Catarina e que serviram de interpretes para os espanhóis em suas viagens de reconhecimento. (FREITAS DA SILVA, 2013, p. 38).

Nesse período, os viajantes cronistas enxergavam os guaranis como guerreiros, os quais permanentemente buscavam ampliar seu território, conquistando e dominando outros grupos étnicos e concebendo-o como os seus escravos ou guerreiros. Outra informação importante sobre os guarani é a sua demografia. Eles são caracterizados como uma população ampla e que se situava em um extenso território. Esses dados estabelecem a configuração de uma população homogênea culturalmente, esparramada através de um vasto espaço geográfico. Numerosos pesquisadores chegam a afirmar que, devido à expansão territorial e cultural dos guaranis, houve uma "guaranização" ao longo desse território.

Entendemos que a guaranização é uma das concepções que se apoia em conceitos como o de aculturação, os quais pensam o encontro entre duas culturas diferentes como um movimento onde uma delas tende a subsumir completamente a outra.

Ou como observou Carlos Rodrigues Brandão quando discutia questões ligadas a identidade e etnia: "Aculturação é o nome do processo através do qual culturas intercambiavam "traços" e "complexos" culturais, de tal sorte que os de uma delas, mais forte, mais impositiva, envolviam os da outra e do encontro surgia uma nova cultura".

Branislava Susnik indiretamente já havia questionado a guaranização dos Chiriguanos ao elaborar um trabalho sobre cultura material indígena, em que observou que no caso das populações de Chiriguanos, por mais que eles sigam pautas tradicionais Guarani, eles também reproduzem pautas de influência arawak e andina e "esto puede observarse también en La alfarería". (FREITAS DA SILVA, 2013, p. 40).

Essa é uma direção de sentido único; aquilo que se absorve de certa população em desvantagem de outras, de modo que, na junção de distintas culturas, não existisse trocas, 
diálogos e intercâmbio culturais. De tal maneira que qualquer contato transformasse os grupos todos em Guarani.

Podemos afirmar que os colonizadores, na sua busca por conquista de territórios, começaram a classificar as populações que encontravam ao longo do seu vasto empreendimento. A nomeação de grupos indígenas segue exatamente, nesse sentido, o ponto de vista que os conquistadores detinham sobre aqueles grupos. Segundo Pierre Bourdieu (1989), a luta entre diferentes grupos sociais ocorrem através de disputas políticas que, na maioria dos casos, extrapola a questão material, acabando sempre por envolver uma dimensão simbólica. Essa última, por sua vez, é designada por ele como uma disputa em torno da classificação do mundo social. Ela se constitui, em outras palavras, na percepção e na realidade. De acordo com ele, as formas de distinção social são construídas a partir de práticas sociais que expressem princípios de diferenciação. No entanto, tal construção não se efetua de maneira simétrica, uma vez que determinadas categorias detém o poder simbólico de "constituir o dado pela enunciação, de fazer ver e fazer crer, de confirmar ou de transformar a visão de mundo, e deste modo, a ação sobre o mundo" (BOURDIEU, 1989, p. 14). Toda luta política, portanto, envolve uma disputa pelo poder de representação, pelo reconhecimento das formas de representação legítima e pelo controle simbólico do agendamento. Ela é, portanto, uma luta pelo poder de nomeação, classificação e categorização dos temas. Estabelecendo padronizações socioculturais fixas, sem levar em conta a diversidade cultural própria desses povos, os colonizadores passaram a fornecer os significados através do quais as populações indígenas deveriam ser compreendidas, ou seja, exerceram seu poder simbólico de impor uma nomeação, e o conjunto de significados que ela carrega, frente a uma heterogeneidade de grupos sociais.

\footnotetext{
Para falarmos de etnônimos e etnificação, iniciamos retirando o exemplo de Sanches Labrador sobre a questão de um grupo que se autodenominava em seu próprio idioma de Eyiguayegui, mas que era classificado por parte dos espanhóis, por meio de dois gentílicos no idioma Guarani, Guaycurú e Mbayá. Nessa situação acreditamos que o antropólogo Eduardo Viveiros de Castro diria que esta seria apenas uma amostra de que a "identificação dos grupos por meio de etnônimos era fruto de uma incompreensão total da dinâmica étnica e política do socius ameríndio". É John Monteiro quem cita Viveiros de Castro na sua Tese Tupi, Tapuias e os Historiadores, quando discutia questões ligadas às identidades coloniais dos grupos (FREITAS DA SIVA, 2013, p. 52).
}

Segundo a interpretação em torno dessa questão, isso se tornou um agravante, pelo fato de que as populações indígenas passaram também a se caracterizar de acordo com a visão que os grupos colonizadores construíram. As formas de classificação criadas pelos europeus 
refletiam, na verdade, os seus objetivos e intenções conforme os princípios da conquista colonial, no que refere à exploração do território, detectar as populações que nele habitam e, posteriormente, dominar a sua geografia.

\begin{abstract}
John Monteiro cita o exemplo das populações consideradas Tupi, estabelecidas em parte do litoral português. Ele observa que em algumas situações, dependendo da relação com determinado grupo, os próprios portugueses lhes atribuíam diferentes classificações. Se fossem amigos eram considerados Tupis, mas no caso de inimigos poderiam entrar no rol dos Tapuias. Para o autor, esses dados levavam a crer que os etnônimos indígenas em muitos contextos possuíam um "caráter historicamente específico". Ou seja, que os grupos indígenas flutuavam sob uma gama de categorias que estabeleciam a sua condição dentro da política colonial, podendo ser num dado momento aliadas, e, em outro momento, inimigos. Podendo existir enquanto grupo aliado, amigo, na qualidade de Tupi ou Moluche, ou serem duramente combatidos e escravizados sob a condição de serem enquadrados como Tapuia ou Auca. (FREITAS de SILVA, 2013, p. 56-57).
\end{abstract}

Podemos inferir que foi dentro desse contexto colonial que aconteceu a essencialização das etnias - ou etnificação dos grupos indígenas. É exatamente esse procedimento de etnificação a consequência de que é observado como exercício colonial de caracterizar e classificar as populações nativas em padrão naturalizado, o momento primordial da dominação colonial. Nessa observação, diversos etnonimos originaram-se ou reproduziram-se durante o primeiro período da colonização, estabelecendo aos povos nativos uma identidade, um idioma, uma área territorial e uma condição no interior da constituição da sociedade colonial.

De acordo com Freitas da Silva (2012, p. 58-59), a etnificação aconteceu quando determinadas estruturas sociais se tornaram Gaurani, Charrua, Minuano, Timbú, Yaró, Chiquito, Payaguá, Guaná. Diversas etnias foram construídas a partir da experiência colonial, sendo elas caracterizadas segundo binômios como inimigo/amigo e bravo/manso. Nessa perspectiva, a característica que sobressaiu em torno da diversidade das populações indígenas se efetivou principalmente por viés das alianças feitas com colonos, assim como, percebemos hoje, em torno da resistência que criaram em relação a esse tipo de contato. No contexto colonial eram vistos como bravos ou inimigos, pelo fato de resistirem à colonização. Dito em outras palavras, a construção de determinadas categorias étnico-culturais, tal como o Guarani, foram processadas através das disputas políticas instituídas no âmbito da sociedade colonial.

\title{
ALDEAMENTO NO PERÍODO COLONIAL
}


Os jesuítas chegaram à América juntamente com as primeiras navegações europeias, trazendo na bagagem uma visão religiosa profundamente em conexão com as doutrinas cristãs da Idade Média. Para eles, as populações nativas da América eram identificadas na gentilidade, cujo termo é da própria instituição religiosa judaico-cristã, ou seja, determinada pessoa que não segue ou não é convertido nessa religião monoteísta. Os índios eram vistos como pessoas sem conhecimento religioso, isto é, uma tabula rasa, conforme os jesuítas precisavam preencher esses vazios com a fé cristã e a razão.

\begin{abstract}
O indígena, segundo esta visão, encontrava-se na gentilidade. O termo gentio é próprio da tradição religiosa judaico-cristã e refere-se àquele que professa religiões não-monoteístas. São pagãos. A expressão gentio é anterior à conquista espiritual dos indígenas da América, mas os espanhóis e lusitanos, como membros da cristandade, consideravam-se continuadores da missão inicialmente conferida aos judeus [...]. A gentilidade é associada na América à barbárie, e até bem recentemente é comum encontrarmos o termo selvagem como sinônimo de índio. Na missão, o índio terá de aprender inclusive a comer, a vestir-se e a comportar-se como cristão. $\mathrm{Na}$ batalha pelo monopólio da santidade entre jesuítas e os Guarani, estes últimos tiveram suas antigas práticas demonizadas. (SOUSA, 2004, p. 27).
\end{abstract}

Nesse período, os indígenas tinham que deixar os seus rituais tradicionais, pelo motivo de muitos desses hábitos serem demonizados pelos jesuítas. Por exemplo, as tatuagens e pinturas que utilizavam em seu corpo foram, durante a missão, duramente combatidas. Se houvesse resistência, ela era reprimida com violência física e psicológica. Aqueles que resistem nesse novo sistema de vida são, geralmente, os xamãs, os quais muitos acabam sendo levados nas reduções como prisioneiros. Essa instituição religiosa é ligada ao sistema colonial espanhol, cujo propósito era o de transformar os indígenas em cristãos. As reduções eram uma estratégia dos jesuítas para fixar os indígenas em um espaço e, assim, realizar as suas missões de catequeses.

A redução é um método missional, que reúne os indígenas em territórios específicos para que vivam uma vida mais política e humana, segundo a concepção religiosa e a ideologia da época (SOUSA, 2004, p. 37). O termo redução predominou entre as missões espanholas da Companhia de Jesus, ao passo que no Brasil os termos aldeamento e missão eram mais utilizados. Os termos misiones e reduciones foram empregados como sinônimos na medida em que pretendiam reduzir os índios à vida civilizada. Após 1655, as missões do Paraguai foram transformadas em doctrinas, ou paróquias, sob a jurisdição diocesana local (SOUSA, 2004, p. 41-42).

A língua era um meio para conseguir a conversão e o resultado era mostrado como positivo por parte dos Guarani, pelo motivo de ser escolhido a língua guarani na redução para 
pregação das palavras de Deus. Nessa redução:

O sistema de educação procurava reproduzir o novo tipo de Guarani a que a missão se propunha: homens cristãos, adaptados ao trabalho comum e alguns deles especializados em ofícios qualificados, mais para as obras necessárias na redução que para o mercado externo. (SOUSA, 2004, p. 38).

As reduções visavam não só reduzir um determinado grupo especifico, mas também reunir diversos grupos étnicos no mesmo espaço físico e social. Essa instituição religiosa se instalou na América do Sul justamente para civilizar e salvar a alma nativa e, sobretudo, legitimar a verdade e o centro da fé cristã para diversas sociedades indígenas. Outro proposito que é importante pontuar seria o de expandir o território e ganhar súditos para a Coroa. Os nativos dessa nova terra eram caracterizados como sub-humanos, por esse motivo precisavam ser civilizados e, com isso, passar para o outro estagio de civilização, mas, para conseguir passar, precisariam abandonar a vida de barbárie.

Em um primeiro momento, os jesuítas tiveram muitas dificuldades para realizar a catequização, devido à falta de recursos para concluir tal objetivo e também porque desconheciam - e impressionaram-se - as diversidades dos povos indígenas. Diante dessa dificuldade, foi pensada como estratégia de catequização a criação de aldeamentos.

De acordo com historiador Moacir Flores, se levarmos em conta as fronteiras politicas atuais, o território da província jesuítica do Paraguai abrangeria as republicas da Argentina, Uruguai, Paraguai, Sul da Bolívia, parte do Sul e centro Oeste do Brasil, formando uma área equivalente a $700.000 \mathrm{~km}^{2}$. (FREITAS da SILVA, 2004, p. 69).

Nessa província, os jesuítas realizavam as suas missões ao longo de 161 anos. Nesse processo, foram constituídos vários aldeamentos de reduções que integraram diversos povos indígenas. Para os aldeamento/reduções, os indígenas foram recolhidos, onde foi dado para eles um espaço de terra para cada família; o espaço para viver, plantar e criar seus animais. A população que aceitou esse novo cotidiano de vida encontrava-se numa situação diferente em relação à sua vida anterior. $\mathrm{O}$ aldeamento/redução tem configuração essencialmente diferente das configurações tradicionais de cada comunidade; era administrado por jesuítas, o cotidiano era imposto por instituição religiosa, seguindo as doutrinas da ordem religiosa. O proposito essencial dos jesuítas é povoar a aldeia buscando os indígenas que morava em terras dispersas. 
Na opinião de João Pacheco de Oliveira, fixar os indígenas em pueblos permanentes era uma forma de territorializá-los. Situação, conforme o autor, que pode ser definido como um processo de reorganização social, que traz consigo implicações como: a "critica de uma nova unidade sociocultural mediante o estabelecimento de uma identidade étnica diferenciadora", a "constituição de mecanismo politico especializados", a "redefinição do controle social sobre os recursos ambientais" e a "reelaboração da cultura e da relação com passado". Para o autor, o processo de territorialização é, justamente, o movimento pelo qual um objeto politico administrativo seria chamado na América espanhola de "redução". (FEITAS da SILVA, 2013, p. 71).

É importante pontuar que a língua guarani era o idioma principal nas reduções, mesmo havendo outras populações de não guarani falantes, os próprios jesuítas generalizam e denominam a redução de guarani.

\begin{abstract}
Para Santos e Batista, por traz da inscrição de guarani havia uma pluralidade étnico relevante que se manteve nas sombras dos escritos históricos. Portanto, afirma que a população reduzida tenha sido oriunda de apenas uma etnia indígena, mesmo que essa seja considerada "Macro Guarani”, não tem apoio nas fontes da época. Mesmo as reduções de guarani eram de indigenas que podiam ser chamados assim, mas tinham uma organização social heterogênea e, pelo menos, um antecedente linguístico e cultura distinto ao dos povos falantes de língua da família Tupi-guarani. Alguns estudos veem esta ação como um ato de essencializar as populações nativas sob etnônimos que as fixavam no tempo e espaço, dando a impressão de que as mesmas preexistiam desde antes da conquista como unidades socioculturais estanques. (FREITAS da SILVA, 2013, p. 81).
\end{abstract}

Essa nomeação servia para organizar os indígenas sob o poder colonial, isto é, para uniformizar distintos povos e forjar uma nova nomeação de acordo com os interesses dos colonizadores. Nas reduções, a pluralidade étnica desaparecia em razão da mudança por viés da conversão. Nesse sentido, havia toda uma pluralidade étnica que, nas reduções, passaram a compartilhar o mesmo espaço; uma diversidade que foi caracterizada como sendo uma mesma cultura e com a mesma denominação.

Nesse contexto, muitos grupos indígenas também desapareceram, mudando-se para o outro lugar, associando-se a outro grupo ou sendo extintos. Alguns relatos históricos constatam que diversos foram exterminados, que desapareciam todas as pessoas da comunidade tradicional. A mobilidade territorial era, muitas vezes, uma estratégia de sobrevivência do grupo, seja deslocando-se pelo receio quanto aos ataques europeus ou por meio da aliança com outro grupo indígena. A partir do século XVII, as reduções foram extintas. Devido a conflitos entre os jesuítas e bandeirantes, nesse período diversas reduções foram destruídas ou abandonas. No entanto, as tentativas políticas de confinamento das 
populações indígenas ainda persistiriam ao longo de séculos.

\section{CONSIDERAÇÕES FINAIS}

No âmbito da Sociologia, as identidades podem ser denominadas, utilizando a expressão cunhada por Benedict Anderson (2008), de "comunidades imaginadas". Dito em outras palavras, a identidade seria um sentimento de pertencimento forjado a partir de narrativas que agregam pessoas de um mesmo grupo a partir características escolhidas arbitrariamente e consideradas comuns a eles.

[...] na verdade, as identidades nacionais não são coisas com as quais nós nascemos, mas são formadas e transformadas no interior da representação. Nós só sabemos o que significa ser "inglês" devido ao modo como a "inglesidade" (Englishness) veio a ser representada - como um conjunto de significados - pela cultura nacional inglesa. Segue-se que a nação não é apenas uma entidade política mas algo que produz sentidos - um sistema de representação cultural. As pessoas não são apenas cidadãos/ãs legais de uma nação; elas participam da ideia da nação tal como representada em sua cultura nacional. Uma nação é uma comunidade simbólica e é isso que explica seu 'poder para gerar um sentimento de identidade e lealdade'. (HALL, 2003, p. 47).

Tal definição, centrada na constituição das identidades nacionais, serve para qualquer tipo de identificação. A identidade, enquanto construção simbólica e discursiva, deve sempre ser encarada a partir de uma perspectiva relacional, como uma forma social de classificação que, de maneira processual, está sendo constantemente renegociada ao longo da experiência social de determinados grupos. As identidades, nesse sentido, somente fazem sentido enquanto categorias de distinção social que certos grupos sociais operacionalizam, em determinadas circunstâncias, em relação a outros.

Stuart Hall (2008) nos alerta para os perigos em se apropriar conceitualmente do termo identidade. Segundo ele, tal conceito é muitas vezes utilizado tendo como pressuposto um sujeito auto-centrado, no qual a identidade estaria presente de forma fixa e estanque. Em suas palavras:

[...] é precisamente porque as identidades são construídas dentro e não fora do discurso que nós precisamos compreendê-las como produzidas em locais históricos e institucionais específicos, no interior de formações e práticas discursivas específicas, por estratégias e iniciativas específicas. Além disso, elas emergem no interior do jogo de modalidades específicas de poder e são, assim, mais o produto da marcação da diferença e da exclusão do que o signo de uma idêntica, naturalmente constituída, de uma 'identidade' em seu significado tradicional - isto é, uma mesmidade que tudo inclui, uma identidade sem costuras, inteiriça, sem diferenciação interna (2008, 
p. 109).

Os colonizadores encontraram dificuldades nas suas tentativas de controlar a pluralidade de grupos indígenas. Nesse contexto que surgiram as nomeações e classificações de diferentes povos indígenas. As nomeações eram conceituadas sob a ótica dos colonizadores. Através das experiências entre colonizadores e colonizados, produziram-se várias identidades, servindo elas para a organização do espaço colonial. No caso dos guarani, foi uma identidade que serviu para fins europeus no sentido de se criar um senso de superioridade entre eles e, assim, justificar as suas estratégias de subalternização perante diferentes povos que habitavam a região que agrega hoje o estado de Mato Grosso do Sul.

\section{REFERÊNCIAS}

BOURDIEU, P. (1989). O poder simbólico. Lisboa: Difel.

CHAMORRO, G. (2015). Historia Kaiowá. Das origens aos desafios contemporâneos. São Bernado do Campo: Nhanduti Editora.

FREITAS da SILVA, A. L. (2013). Reduções Jesuítico-Guarani. Espaço de diversidade étnica. São Bernado do Campo: Nahnduti Editora.

HALL, S. (2003). A identidade cultural na pós-modernidade. São Paulo: DP\&A Editora.

HALL, S. (2008) "Quem precisa de identidade". In: SILVA, Tomaz Tadeu; HALL, Stuart; WOODWARD, Kathryn (org.). Identidade e diferença. A perspectiva dos estudos culturais. Petrópolis: Editora Vozes.

QUIJANO, A. (2005) Colonialidade do poder, eurocentrismo e América Latina. Buenos Aires: CLACSO.

SOUSA, N. M. (2004). A Redução de nuestra Señora de Fe no Itatim: entre a cruz e a espada. Campo Grande: UCDB.

MARTINS, G. R.(2002). Breve Painel Etno-histórico de Mato Grosso do Sul. Campo Grande: Editora UFMS. 